Article

\title{
Effects of Backpack Loads on Leg Muscle Activation during Slope Walking
}

\author{
Yali Liu ${ }^{1} \mathbb{C}$, Ligang Qiang ${ }^{2}$, Qiuzhi Song ${ }^{1}$, Mingsheng Zhao $^{1}$ and Xinyu Guan ${ }^{3, *}$ \\ 1 Department of Mechanical and Engineering, Beijing Institute of Technology, Haidian, Beijing 100081, China; \\ buaaliuyali@126.com (Y.L.); qzhsong@bit.edu.cn (Q.S.); 18351898665@163.com (M.Z.) \\ 2 Robot Research Institute, Guizhou Aerospace Control Technology co., LTD, Economic and Technological \\ Development District, Guiyang 550000, China; qiangligang123@163.com \\ 3 Division of Intelligent and Biomechanical System, State Key Laboratory of Tribology, Tsinghua University, \\ Haidian, Beijing 100086, China \\ * Correspondence: guanxinyu@mail.tsinghua.edu.cn
}

Received: 15 June 2020; Accepted: 13 July 2020; Published: 16 July 2020

check for updates

\begin{abstract}
Hikers and soldiers usually walk up and down slopes with a load carriage, causing injuries of the musculoskeletal system, especially during a prolonged load journey. The slope walking has been reported to lead to higher leg extensor muscle activities and joint moments. However, most of the studies investigated muscle activities or joint moments during slope walking without load carriage or only investigated the joint moment changes and muscle activities with load carriages during level walking. Whether the muscle activation such as the signal amplitude is influenced by the mixed factor of loads and grades and whether the influence of the degrees of loads and grades on different muscles are equal have not yet been investigated. To explore the effects of backpack loads on leg muscle activation during slope walking, ten young male participants walked at $1.11 \mathrm{~m} / \mathrm{s}$ on a treadmill with different backpack loads (load masses: 0, 10, 20, and $30 \mathrm{~kg}$ ) during slope walking (grade: 0, 3, 5 , and $\left.10^{\circ}\right)$. Leg muscles, including the gluteus maximus (GM), rectus femoris (RF), hamstrings (HA), anterior tibialis (AT), and medial gastrocnemius (GA), were recorded during walking. The hip, knee, and ankle extensor muscle activations increased during the slope walking, and the hip muscles increased most among hip, knee, and ankle muscles (GM and HA increased by $46 \%$ to $207 \%$ and $110 \%$ to $226 \%$, respectively, during walking steeper than $10^{\circ}$ across all load masses (GM: $p=1.32 \times 10^{-8}$ and HA: $\left.p=2.33 \times 10^{-16}\right)$ ). Muscle activation increased pronouncedly with loads, and the knee extensor muscles increased greater than the hip and ankle muscles (RF increased by $104 \%$ to $172 \%$ with a load mass greater than $30 \mathrm{~kg}$ across all grades (RF: $p=8.86 \times 10^{-7}$ )). The results in our study imply that the hip and knee muscles play an important role during slope walking with loads. The hip and knee extension movements during slope walking should be considerably assisted to lower the muscle activations, which will be useful for designing assistant devices, such as exoskeleton robots, to enhance hikers' and soldiers' walking abilities.
\end{abstract}

Keywords: muscle activations; electromyography; slope walking; backpack loads

\section{Highlights}

- Hip extensor muscle activations increase most during slope walking;

- Muscles increased pronouncedly during slope walking with backpack loads;

- Knee extensor muscle activations increased most with increasing backpack loads. 


\section{Introduction}

Hiking is a popular exercise providing benefits, including the acceleration of calorie consumption and the burning of fat tissue [1,2]. Hiking on slopes and with backpack loads can cause pain and injuries of the musculoskeletal system, especially during a prolonged load journey [3-5].

Walking with load carriage leads to high energetic consumptions and joint moments. Many studies have explored the energetics and kinematics with different backpack loads during level walking [6-10]. Karen et al. [6] analyzed the energy cost of walking with and without a backpack load and pointed out that the load increased the oxygen uptake at a constant rate. Raymond et al. [7] further analyzed the effects of load masses added to the legs on energetics and biomechanics. They summarized that the metabolic rate increased with the load mass and the kinematics and muscle moments increased rapidly with loads at the feet. Additionally, the increased metabolic rate with the load carriage may be caused by increased ankle positive work during push-off [8]. Morrison et al. [9] also analyzed the motion entropy changes to the load carriage at a joint level and pointed out that the entropy of spine slide flexion increased while hip flexion entropy decreased. Kari et al. [11] pointed out the sex effect on the kinematics with loads: females used more hip and knee moments with loads compared to males during walking. Furthermore, Krajewski [12] studied the effect of load carriage magnitudes and different locomotion patterns (fast run and force marching) on knee moments.

Most studies investigating load carriages suggest a positive correlation exists between load mass and joint moments, as well as energetics. However, joint moments or joint work in one gait calculated by joint moments and angular displacement do not account for muscle activations during load carriage walking [13]. Researchers have made explorations into the muscle activation patterns during level walking with load carriages $[4,5,14]$. Karina et al. [4] found that the muscle activity changed differently with increased load masses to adjust to maintain balance and attenuate the loads placed on lower limbs. The muscle activations of the soleus, medial gastrocnemius (GA), lateral hamstrings (HA), and rectus femoris (RF) increased with load, and the muscle activation patterns were similar between men and women [5]. Kenneth et al. [14] studied the musculoskeletal stiffness during load carriages at different walking speeds and found the musculoskeletal stiffness increased as a function of both speed and load. Walsh et al. [15] investigated the effect of stable and unstable load carriages on muscles of older adults. They pointed out that unstable load carriages increased the activity of the RF and soleus, while stable load carriages increased the RF activity.

Subjects such as soldiers and hikers who habitually walk uphill with load carriages usually feel tired because of muscle fatigue. It is important to design assistive devices for soldiers and hikers according to the load carriage effects. A backpack load, for example, increases the dynamic forces on the human body. Huang et al. [16] and Yang et al. [17] designed suspended-load backpacks as an assistive device to reduce the dynamic forces.

Slope walking has been reported to lead to greater leg extensor muscle activities and joint moments. However, most of the studies investigated muscle activities [18-20] or joint moments [21-24] during slope walking without load carriages or only investigated the joint moment changes $[9,10,12]$ and muscle activities $[15,16,25]$ with load carriages during level walking. Whether the muscle activations such as the signal amplitude are influenced by the mixed factor of load mass and grade and whether the influence of the degrees of load mass and grade on different muscles are equal have not yet been investigated. It is important to know how the muscles are activated during one gait when slope walking with backpack loads for designing assistive devices, such as exoskeleton robots, to enhance people's movement abilities with backpack loads.

This study aimed at investigating the effects of load carriages on muscle activities during slope walking to provide suggestions for the design of assistive devices. We hypothesized that (1) hip, knee, and ankle extensor muscle signal amplitudes during one gait would increase during the slope walking compared to level walking, especially the hip extensor muscles, such as the gluteus maximus (GM) and $\mathrm{HA}$; (2) the muscle signal amplitudes would increase pronouncedly with loads during slope walking; (3) the muscle signal amplitudes would increase at different degrees. The knee extensor muscles, 
such as the RF, would be activated more compared to the hip and ankle extensor muscles, such as GM, $\mathrm{HA}$, and GA.

\section{Methods}

\subsection{Subjects}

Ten young male adults volunteered for this study (mean \pm standard deviation; age: $24.10 \pm 1.79$ years, height: $175.30 \pm 5.12 \mathrm{~cm}$, and mass: $69.40 \pm 8.15 \mathrm{~kg}$ ). All subjects were familiar with treadmill walking and had no neuromuscular, cardiovascular, or orthopedic diseases. All subjects were provided with the informed consent form for the experiment, and the experiment was approved by the Ethics Committee of Beijing Sport University (No. 2019007H (2019.01-2021.01)).

\subsection{Experimental Protocol}

Subjects walked on a force treadmill (Bertec, Columbus, OH, USA), on which the walking grade and walking speed could be adjusted accordingly. Each subject was familiarized with walking on the treadmill for about $5 \mathrm{~min}$ with the walking speed set to $1.11 \mathrm{~m} / \mathrm{s}$ and the walking grade set to $0^{\circ}$. The speed of $1.11 \mathrm{~m} / \mathrm{s}(4 \mathrm{~km} / \mathrm{h})$ was selected according to the American College of Sports Medicine [22] and the literature on uphill and downhill walking [23]. Each subject was required to walk for $2 \mathrm{~min}$ on the treadmill with three mass backpack loads $\left(10,20\right.$, and $30 \mathrm{~kg}$ ) during four grades (level $\left(0^{\circ}\right)$, 3,5 , and $10^{\circ}$ grades). The level and slope walking on the treadmill without loads $(0 \mathrm{~kg})$ were also completed by each subject as a reference. Subjects were asked to perform all the load mass tests at one certain grade in order to shorten the experiment time. The load masses were in random order during one grade test, and the grade testes were also in random order. Subjects were asked to walk at one grade for $3 \mathrm{~min}$ with one load during one trial. Subjects rested for 3 min between different load mass trials and $30 \mathrm{~min}$ between different grade tests. The experimenters adjusted the load mass and the walking grade while the participants rested. The speed of the treadmill was set to $1.11 \mathrm{~m} / \mathrm{s}$ in every trial. The temporal stride kinematics and surface electromyographic (EMG) during the final $30 \mathrm{~s}$ of each trial were recorded.

The temporal stride kinematics were calculated according to the ground force data recorded by the force platform in the treadmill. Two force platforms were embedded in the treadmill and recorded the ground interactive forces and moments between foot and ground. The software in the optical motion-capture system (Motion, Columbus, OH, USA) [26] calculated the center of force operation based on the forces and moments.

The EMG signals were collected by the wireless EMG system (Delsys Trigno ${ }^{\mathrm{TM}}$ Wireless EMG System (Natick, MA, USA)). The muscles selected included the GM, RF, HA, anterior tibialis (AT), and GA, which are the main activated muscles during human lower extremity movements [27]. The pre-amplified single differential electrodes (Trigno, Delsys, Natick, MA, USA) were placed on the muscle bellies after preparing the skin with alcohol (the schematic diagram of human lower limb muscles in this study is shown in Figure 1). The surface EMG (sEMG) signal sensors were fixed with double-sided tapes and bandages to prevent displacement between the sensors and muscles during walking.

This optical motion capture system (Motion, Columbus, OH, USA) can integrate the Delsys device and the Bertec force platforms by a data acquisition card (DAQ, National Instruments, Austin, TX, USA); thus, the sEMG signal and kinetic data can be collected simultaneously. The sampling frequency was selected as $1200 \mathrm{~Hz}$. 

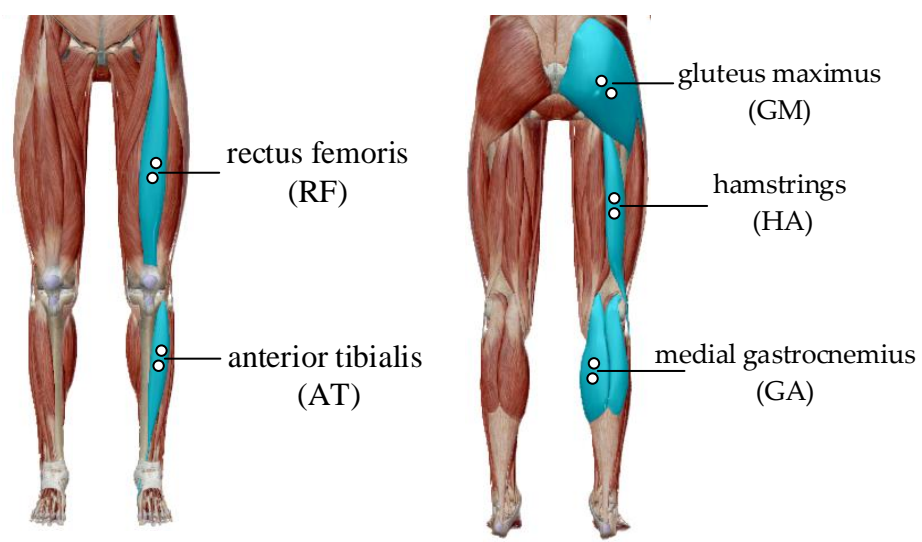

Figure 1. The schematic diagram of the human lower limb muscles in this study. The position of the two white points on one muscle represented the position of the electromyographic (EMG) electrodes attached.

\subsection{Data Analysis}

\subsubsection{The Temporal Stride Parameters}

The kinetic data were obtained by the output of the software provided by the optical motion-capture system (Cortex-64, Santa Rosa, CA, USA), which was linked with the force treadmill system (Bertec, Columbus, $\mathrm{OH}, \mathrm{USA}$ ). Raw kinetic data were smoothed using a 4th-order Butterworth filter with a cutoff frequency of $10 \mathrm{~Hz}$ [28]. We then used vertical ground reaction force data and a threshold of $20 \mathrm{~N}$ (on the basis of the standard deviation of the vertical ground reaction force signal during leg swing) [29] to determine the heel strike and toe-off for each leg and computed the temporal characteristics of each trial using custom software (MathWorks Inc., Natick, MA, USA). The step length was determined as the distance between the point where the left heel strike occurred and the point where the right heel strike occurred in the walking direction, and the step width was determined as the distance between the two heel strike points in the walking transverse distance [30].

\subsubsection{The EMG Analysis}

The raw EMG signals were filtered by a bidirectional Butterworth band-pass filter with cutoff values of 20 and $500 \mathrm{~Hz}$ [31,32] in a custom script written in MATLAB (MathWorks Inc., Natick, MA, USA). The signals were full-wave rectified and filtered by a low-pass filter at $10 \mathrm{~Hz}[33,34]$. The filtered EMG signals were then used to calculate the root mean square (RMS EMG) with a window of $10 \mathrm{~ms}$ to describe the muscle activation during movement [33]. In addition, the filtered EMG signals were used to calculate the mean of the EMG (MEMG) to describe the work of one muscle during movement. Since the gait cycle was usually normalized to $0 \sim 100 \%$, the sEMG data acquired synchronously should be also interpolated into $0 \sim 100 \%$ to describe how the muscles were activated during the gait $[34,35]$. Therefore, all the RMS EMGs were interpolated into 101 points corresponding to the gait cycle.

\subsection{Statistical Analysis}

We calculated the mean values of step length, step width, and RMS EMG, as well as MEMG, over ten consecutive strides. We then normalized the temporal stride parameters and determined the EMG parameters by calculating the ratio of the values during slope walking with loads to the values during level walking without loads. We used a two-factor (grade $\times$ load mass) analysis of variance for repeated measures to test the significant effects of the grade and load masses. When there was a significant effect $(p<0.05)$, Bonferroni corrected post hoc comparisons (adjusted $p<0.0072(0.05 / 7$, two dependent stride variables and five sEMG variables) $[18,22-24,36]$ were carried out to evaluate the 
differences between the grades and load masses. All statistical analyses were conducted using SPSS software (IBM SPSS Statistics 22).

\section{Results}

\subsection{Temporal Stride Kinematics}

As the load mass and grade increased, subjects took a longer step length than level walking (Table 1). The changes in the normalized step widths were different between the load mass and grade groups. Both of the temporal stride kinematics were not significantly different from level walking without backpack loads (all $p>0.05$ ).

Table 1. Normalized step lengths and step widths during different grades of walking with different load masses.

\begin{tabular}{ccccccccc}
\hline & \multicolumn{3}{c}{ Normalized Step Length } & \multicolumn{3}{c}{ Normalized Step Width } \\
\cline { 2 - 8 } & $\mathbf{0}^{\circ}$ & $\mathbf{3}^{\circ}$ & $\mathbf{5}^{\circ}$ & $\mathbf{1 0}^{\circ}$ & $\mathbf{0}^{\circ}$ & $\mathbf{3}^{\circ}$ & $\mathbf{5}^{\circ}$ & $\mathbf{1 0}^{\circ}$ \\
\hline \multirow{2}{*}{$0 \mathrm{~kg}$} & 1.00 & 1.07 & 1.03 & 1.08 & 1.00 & 1.03 & 1.04 & 1.02 \\
& & $(0.06)$ & $(0.06)$ & $(0.07)$ & & $(0.05)$ & $(0.07)$ & $(0.05)$ \\
$10 \mathrm{~kg}$ & 1.06 & 1.10 & 1.06 & 1.05 & 0.98 & 0.98 & 1.04 & 1.02 \\
& $(0.06)$ & $(0.09)$ & $(0.10)$ & $(0.09)$ & $(0.08)$ & $(0.06)$ & $(0.06)$ & $(0.06)$ \\
$20 \mathrm{~kg}$ & 1.09 & 1.13 & 1.10 & 1.10 & 1.04 & 0.98 & 0.95 & 1.07 \\
& $(0.05)$ & $(0.09)$ & $(0.08)$ & $(0.08)$ & $(0.06)$ & $(0.09)$ & $(0.06)$ & $(0.01)$ \\
$30 \mathrm{~kg}$ & 1.10 & 1.08 & 1.06 & 1.02 & 1.09 & 1.00 & 0.97 & 1.03 \\
& $(0.08)$ & $(0.06)$ & $(0.08)$ & $(0.06)$ & $(0.09)$ & $(0.08)$ & $(0.07)$ & $(0.05)$ \\
\hline
\end{tabular}

All the step lengths and step widths were divided by the values during level walking without backpack loads. Therefore, the normalized step lengths and step widths were " 1.00 ", and all the normalized step lengths and step widths were dimensionless in Table 1.

\subsection{Muscle Activities}

As expected, the mean muscle activities of the hip, knee, and ankle extensors generally increased with the increase of the load mass and grade (Figures 2-5 and Table S1). Both the grade and load mass had a significant effect on all muscles $(p<0.05)$, and none of the muscles showed significant grade-load-mass interactions $(p>0.05)$.

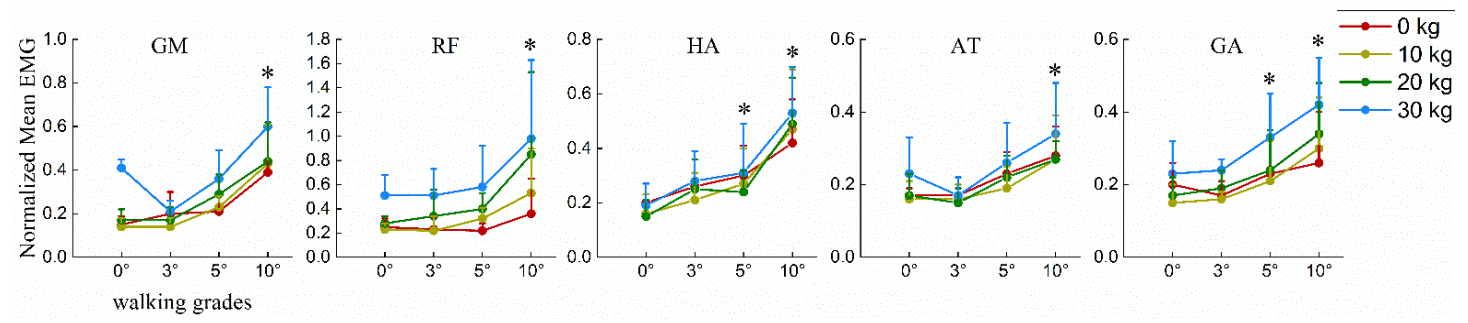

Figure 2. The mean EMG signals for muscles during different slope walking across all load masses in one gait from right heel strike to the next right heel strike, normalized to the mean activity during level walking without backpack loads. ${ }^{*}$ Representing the mean EMG was significantly different from level walking across all the backpack loads, according to post hoc comparisons with a Bonferroni adjusted level of significance $(p<0.0072)$. The red line represented the normalized mean EMG of each muscle at different grades without backpack loads. The yellow one represented the normalized mean EMG of each muscle at different grades with 10-kg backpack loads. The green one represented the normalized mean EMG of each muscle at different grades with 20-kg backpack loads. The blue one represented the normalized mean EMG of each muscle at different grades with 30-kg backpack loads. 

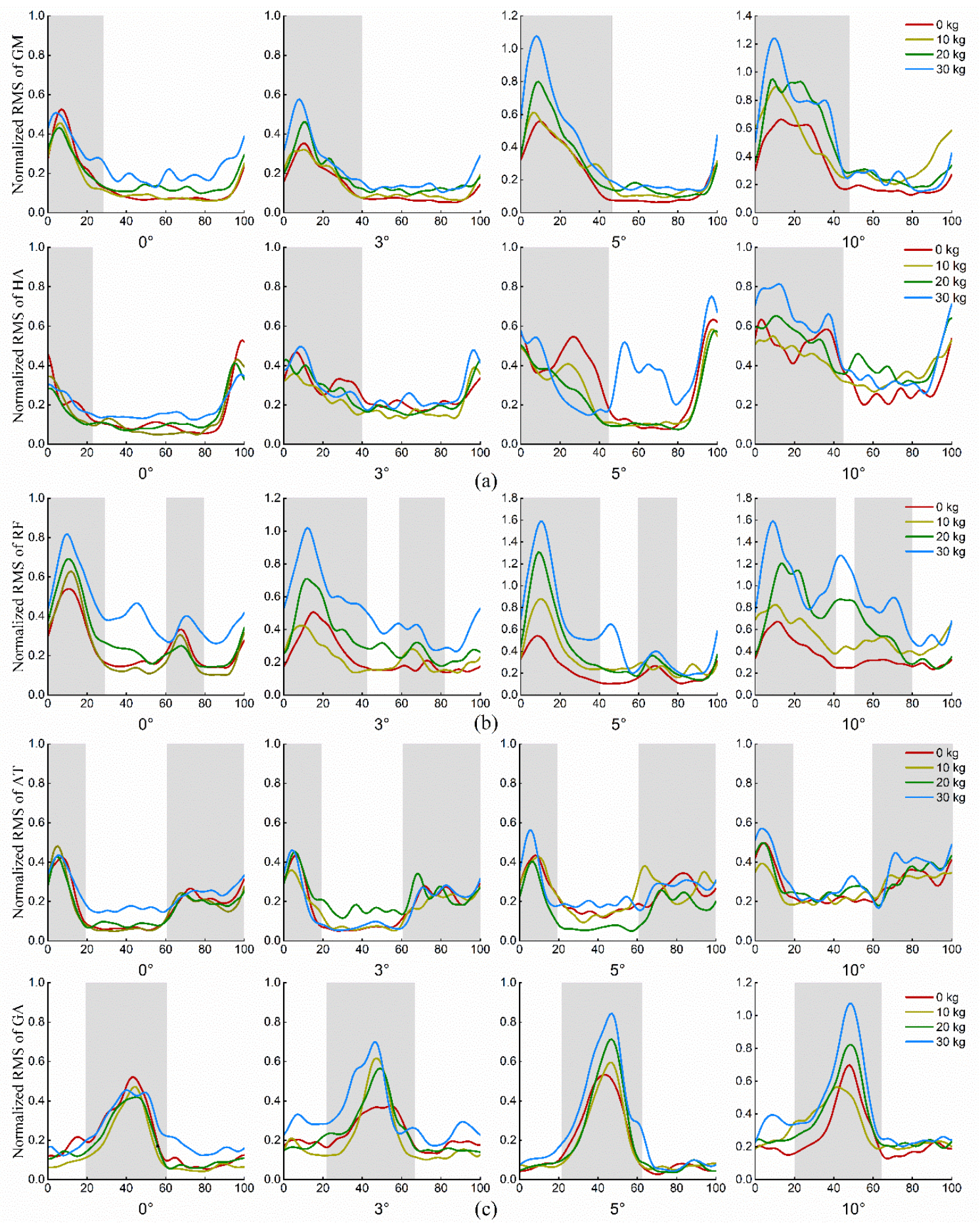

Figure 3. The muscle activity of leg muscles in one gait during different slope walking across all backpack loads, normalized to the mean activity during level walking without backpack loads: (a) The muscle activity of the hip extensor muscles. (b) The muscle activity of the knee extensor muscles. (c) The muscle activity of the ankle muscles. The different colors of the curves had the same representation as those colors in Figure 2. The gray area represented the higher muscle activation duration in one gait. RMS: root mean square. 


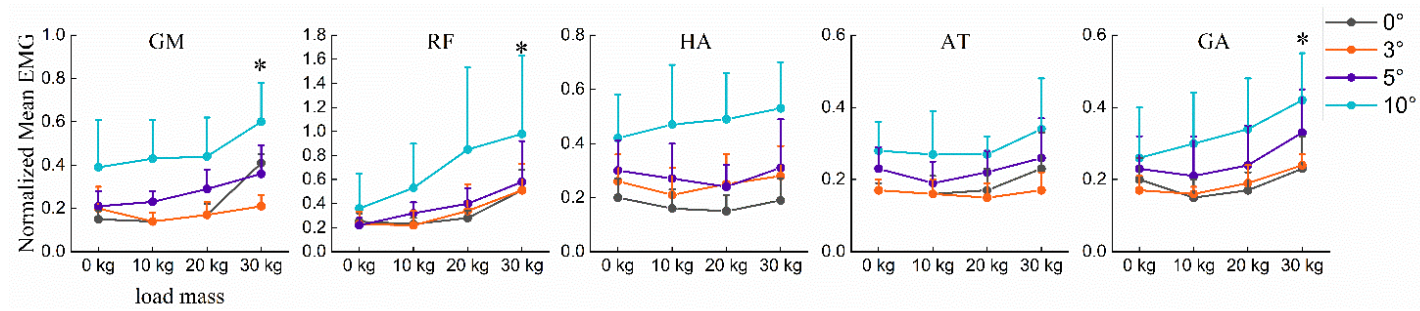

Figure 4. Mean EMG signals for muscles while walking across all grades with different backpack loads during one gait from right heel strike to the next right heel strike, normalized to the mean activity during level walking without backpack loads. * Representing the mean EMG was significantly different from walking without backpack loads across all the grades, according to post hoc comparisons with a Bonferroni adjusted level of significance $(p<0.0072)$. The line in dark gray represented the normalized mean EMG of each muscle with different load masses during level walking. The line in orange represented the normalized mean EMG of each muscle with different load masses during slope walking at grade $3^{\circ}$. The line in purple represented the normalized mean EMG of each muscle with different load masses during slope walking at grade $5^{\circ}$. The line in blue represented the normalized mean EMG of each muscle with different load masses during slope walking at grade $10^{\circ}$.
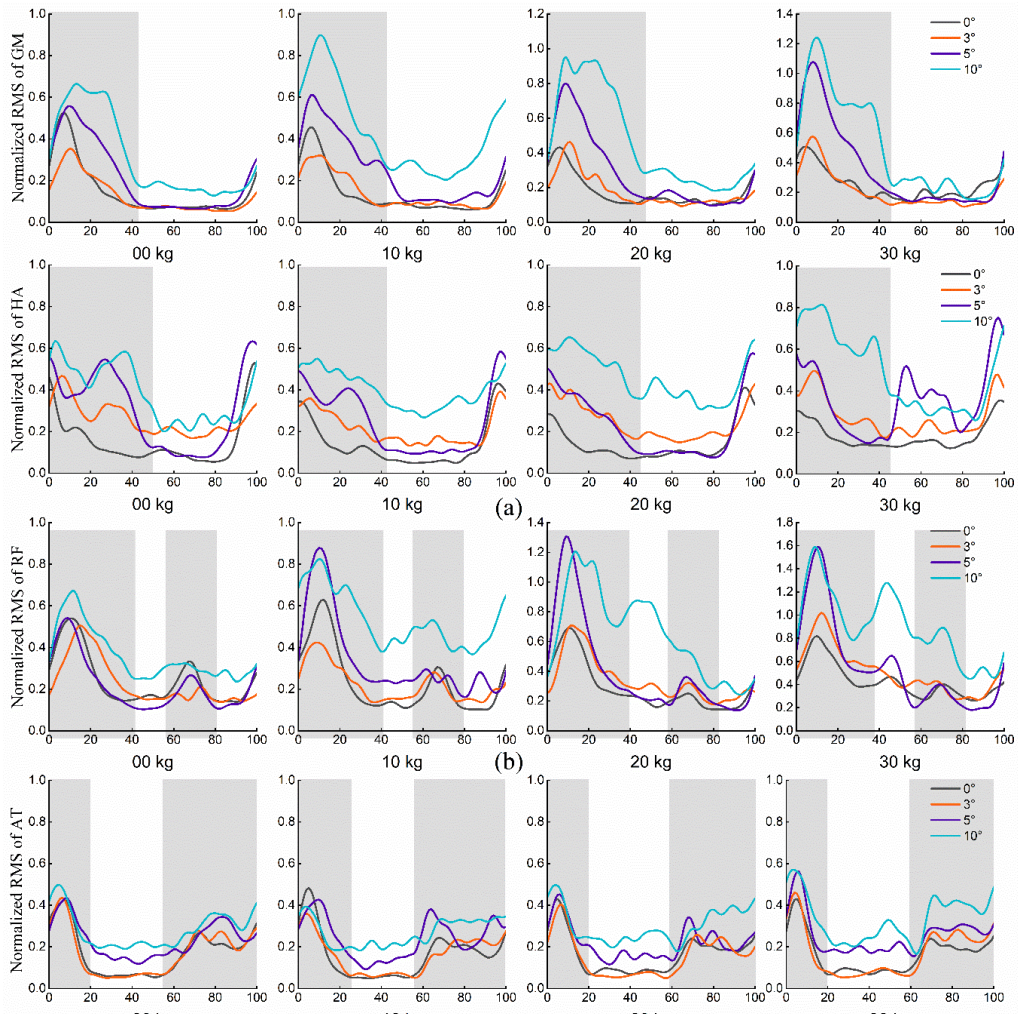

$20 \mathrm{~kg}$
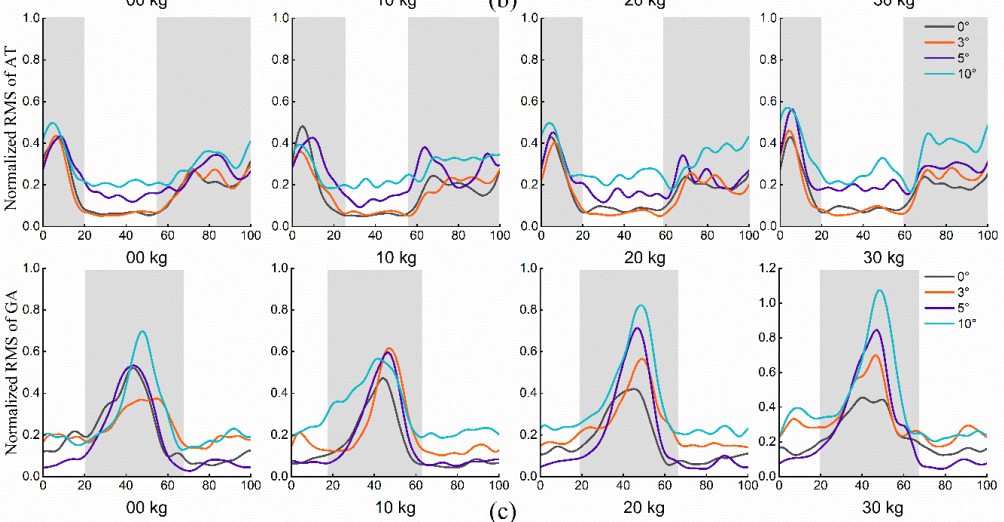

Figure 5. The muscle activity of leg muscles in one gait during walking with different backpack load masses across all grades, normalized to the mean activity during level walking without backpack loads: (a) The muscle activity of the hip extensor muscles. (b) The muscle activity of the knee extensor muscle. (c) The muscle activity of the ankle muscles. The different colors of the curves had the same representation as those colors in Figure 4. The gray area represented the higher muscle activation duration in one gait. 


\subsubsection{Grade Effects}

The mean EMG signals of the hip, knee, and ankle extensor muscles increased generally during most of the slope walking, especially during the $10^{\circ}$ slope walking (GM, $p=1.32 \times 10^{-8} ; \mathrm{HA}, p=2.33 \times 10^{-16}$; $\mathrm{RF}, p=0.2 \times 10^{-5}$; and GA, $p=6.74 \times 10^{-9}$ ). Compared to the level walking, these increases were statistically significant for $\mathrm{GM}, \mathrm{RF}$, and $\mathrm{AT}$ at the $10^{\circ}$ grade and for $\mathrm{HA}$ and $\mathrm{GA}$ at the $5^{\circ}$ and $10^{\circ}$ grades (Figure 2). Compared to the level walking with the same loads, the mean EMG of GM increased greatly during walking at the $10^{\circ}$ grade by $46 \%$ to $207 \%$, HA increased by $110 \%$ to $226 \%$, RF increased by $44 \%$ to $203 \%$, AT increased by $48 \%$ to $68 \%$, and GA increased by $30 \%$ to $100 \%$ (shown in Table S2).

As the grade increased, the muscle activity of the hip extensor muscles (GM and HA, especially $\mathrm{GM}$ ) increased both in the activation value and duration (Figure 3a). The maximum activation value of the GM changed from 0.52 to 1.24 , and the activation duration increased from about $28 \%$ to $48 \%$ of one gait as the grade increased. The maximum activation value of the HA changed from 0.52 to 0.81 , and the activation duration changed from $20 \%$ to about $45 \%$ of one gait as the grade increased.

The muscle activity of the knee extensor muscle (RF) increased most in the activation value, shown in Figure 3b. The maximum activation value of the RF increased from 0.82 to 1.60 during the early stance stage and from 0.4 to about 0.9 during the early swing stage.

As expected, the muscle activity of the ankle extensor (GA) increased considerably in the muscle activation value (Figure 3c). The maximum activation of the GA during the median and the late stances increased highly, from 0.52 to 1.07 . Compared to the ankle extensor, the muscle activity of the ankle dorsiflexion (AT) increased slightly, from 0.48 to 0.57 during the early stance stage and swing stage.

\subsubsection{Load Mass Effects}

The mean EMG signals of the hip, knee, and ankle extensor muscles increased generally as the backpack load masses increased. Compared to walking without backpack loads, the increases were statistically significant for the GM and GA during walking with 30-kg loads (GM, $p=0.000091$ and $\mathrm{GA}, p=0.00091)$ and for the RF during walking with $30 \mathrm{~kg}\left(p=8.86 \times 10^{-7}\right)$ (Figure 4). The increases in the HA and AT were not statistically significant $(p>0.0072)$. Compared to walking without loads at the same grade, the mean EMG of the GM increased by $5 \%$ to $173 \%$ with a $30-\mathrm{kg}$ backpack load, the HA increased by $-5 \%$ to $26 \%$, the RF increased by $104 \%$ to $172 \%$, the AT increased by $0 \%$ to $35 \%$, and the GA increased by $15 \%$ to $61 \%$ (the data are shown in Table S3).

The muscle activity of the hip extensors (GM and HA) increased as the backpack load mass increased, as shown in Figure 5a. The maximum muscle activity of the GM increased greatly from 0.66 to 1.24 as the backpack load mass increased from 0 to $30 \mathrm{~kg}$. The maximum muscle activity of the HA increased slightly from 0.63 to 0.81 as the load mass increased.

The knee extensor muscle RF increased greatly in muscle activation as the backpack load mass increased (Figure 5b). The maximum muscle activation of the RF increased greatly from 0.67 to 1.60 during the early stance stage as the load mass increased from 0 to $30 \mathrm{~kg}$ across all the slope walking.

The ankle extensor muscle GA increased greatly in muscle activation from 0.70 to 1.07 as the backpack load mass increased from 0 to $30 \mathrm{~kg}$, and the dorsiflexion muscle AT increased slightly, from 0.50 to 0.58 (Figure $5 \mathrm{c}$ ). The muscle activity demonstrated that the ankle extensor muscles were activated more than the flexor muscles during slope walking with backpack loads.

\section{Discussion}

This study quantified the hip, knee, and ankle muscle activations during level and slope walking with different backpack loads. Compared to level walking, the hip, knee, and ankle muscle activations increased generally during slope walking, especially the hip extensor muscle activations. The increased mean EMG of the leg muscles in this study were consistent with published findings [4,5,18-20]. Moreover, the increase became more pronounced with backpack loads, especially the hip and knee muscle activations. The hip extensor muscles increased the most with grades changing, and the knee 
extensor muscles increased the most with loads changing, which expanded our knowledge of muscle activation strategies during slope walking with backpack loads.

The results of this study supported our first hypothesis that the hip, knee, and ankle extensor muscle activations would increase during the slope walking, especially the hip extensor muscle activations, compared to level walking. In this study, all the leg extensor muscle activations increased during slope walking to raise the body's center of mass, which were consistent with prior studies [18-20]. In addition, the hip extensor muscle activations (GM and HA) increased remarkably more (the GM increased by $46 \%$ to $207 \%$ and the HA increased by $110 \%$ to $226 \%$ ) than the ankle extensor muscle (GA increased by $30 \%$ to $100 \%$ ) at steeper grades. The activation value and duration of the hip extensor muscles increased remarkably at the early stance stage during slope walking (shown in Figure 2). This demonstrates the pronounced role of hip extensor muscles during slope walking [18,23], which was also described by the greatest increase of the hip extension moment (increased from 1.01 to 1.37 when the treadmill gradient increased from $0 \%$ to $20 \%$ [22]) and the greatest increased power of the hip extensor muscles (increased by $85 \%$ at push-off and by $75 \%$ during mid-stance while walking on uneven terrain [21]). The hip extensors provided greater acceleration of the COM and generated more power for the trunk and ipsilateral leg during slope walking [19], which may also be the reason that the hip extensor muscles were more pronouncedly activated on slopes in our study.

The results of this study also supported our second hypothesis that muscle activations would increase pronouncedly with backloads during slope walking. The increases of the GM, RF, and GA became significant statistically when slope walking with a big backpack load $(30 \mathrm{~kg})$. Consistent with previous investigations $[4,37,38]$, the mean amplitude of the RF and GA increased with loads in this study. The RF activation increased to provide more force and energy to extend the knee to attenuate the impact forces with heavy load carriage [38] and to maintain lower limb stability as the load mass increased [4]. The increase of the GA activations provided more power for walking by increasing the plantar flexing [38], which was thought to overcome the inertia associated with increasing backpack loads [39]. However, the mean EMG of the AT increased in this study, while the average amplitude of the AT remained unaffected $[37,38]$. This difference may be caused by different experimental designs in our study and theirs. The walking conditions in our study were slope walking with backpack loads, while their studies' conditions involved level walking. People elicited larger AT activity during slope walking to provide greater ankle dorsiflexion than level walking $[19,22,28]$. The slope grades may enlarge the influence of backpack loads on muscles.

The results of this study supported our third hypothesis that the muscle activations would increase at different degrees, and the knee extensor muscles would be activated more compared to the hip and ankle extensor muscles. Compared to walking without loads at the same grade across all slope walking, the mean EMG of the knee extensor muscle (RF) increased significantly by $104 \%$ to $172 \%$ with $30-\mathrm{kg}$ backpack loads. The increase of the knee extensor muscle was much greater than that of the ankle extensor muscle (GA increased by $15 \%$ to $61 \%$ with $30-\mathrm{kg}$ backpack loads relative to without loads across all grades). The knee extensor muscle increased most to provide greater force for body support during the early stance stage, which was consistent with other investigations $[18,38,40]$. Except for the knee extensor muscle activations, the hip extensor muscle GM activations also increased more pronouncedly than the ankle extensor muscle GA (GM increased by $5 \%$ to $173 \%$ ). With the loads increasing, the energy and power for walking increased greatly $[7,10]$. The hip extensor muscle GM played an important role in the acceleration of the trunk [19]. Thus, the GM activations increased pronouncedly to provide more power for the acceleration of the trunk as the backpack loads increased. The results implied that the leg extensor muscles may have different contributions during walking with backpack loads. The knee extensor and hip extensor muscles may play a greater role during walking with heavy loads, which was also speculated by Harman [38].

In our present study, the EMG of the GM, HA, RF, AT, and GA were analyzed to investigate the muscle strategy during slope walking with backpack loads. However, one limitation of our study is that we did not acquire the kinematic data in the experiment that may give force to our work. 
In addition, another limitation of our study is that the muscles analyzed were relatively few and most of them were focused on the leg extensor muscles. The muscles around the trunk, such as the external oblique muscles, were not analyzed in this study, which influenced pronouncedly during the inclined walking with backpack loads. The vastus medialis and vastus lateralis at the knee joint were influenced a lot during slope walking to provide more forces for lower limb stability $[18,19]$, which were also not analyzed in this study. Thus, we should acquire the kinematics data and analyze more muscles by experiment or simulation $[19,41]$ in the future to expand the insights into the muscle strategy during slope walking with backpack loads. Finally, considering the load intensity, only male participants were recruited in this study. Males and females may have different muscle-activation strategies during slope walking with backpack loads. Future studies may be needed to understand how muscle activations are influenced by the grade and loads using female subjects.

\section{Conclusions}

In this study, we explored the effects of backpack loads on leg muscle activations during slope walking. It was concluded that the hip, knee, and ankle extensor muscle activations increased during slope walking, and the hip muscle increased the most among the hip, knee, and ankle muscles. Moreover, muscle activations increased pronouncedly with loads during slope walking, and the knee extensor muscle activations increased more than the hip and ankle muscles. The results in our study imply that the hip and knee muscles play an important role during slope walking with loads. Our results are important for the design of assistant devices, such as exoskeleton robots, to enhance people's walking ability, especially for hikers and soldiers. The hip and knee extension movements during slope walking should be considerably assisted to lower the muscle activations. Future studies could explore the effects of loads and grades on more muscles and involve more participants, including female subjects, to expand the insights into the muscle strategy for providing more suggestions for the design of assistant devices.

Full postal address: Room A1043, Lee Shao Kee S\&T Building, Department of Mechanical Engineering, Tsinghua University, Beijing 100084, China.

Supplementary Materials: The following are available online at http://www.mdpi.com/2076-3417/10/14/4890/s1: Table S1: Normalized mean (mean \pm SD) EMG activities during inclined walking with a range of backpack loads, Table S2: The ratio of the EMG between inclined walking and level walking across all backpack loads, Table S3: The ratio of the EMG between walking with backpack loads and without backpack loads across all grades.

Author Contributions: Conceptualization, Y.L. and Q.S.; methodology, X.G.; software, Y.L. and M.Z.; validation, Y.L. and M.Z.; formal analysis, X.G.; investigation, Y.L. and L.Q.; resources, M.Z.; data curation, Y.L., L.Q., and M.Z.; writing-original draft preparation, Y.L.; writing-review and editing, Q.S. and X.G.; visualization, Y.L., L.Q., Q.S., and X.G.; supervision, X.G.; project administration, Y.L.; and funding acquisition, Q.S. All authors have read and agreed to the published version of the manuscript.

Funding: The study was funded by grants from the National Natural Science Foundation of China (Grant No. 51905035 and 51905291), the China Postdoctoral Science Foundation-funded project (Grant No. 2019M660478), and the Ministry of Science and Technology national key R\&D program (Grant Number: 2017YFB1300500).

Acknowledgments: We thank Yue Zhou and Peidong Ma from Beijing Sports University for providing the lab experiments and giving suggestions for the analysis. We thank all the participants in this study.

Conflicts of Interest: The authors have no conflict of interest concerning this manuscript.

\section{References}

1. Nordb, I.; Prebensen, N.K. Hiking as mental and physical experience. In Advances in Hospitality and Leisure; Emerald Group Publishing Limited: Bingley, UK, 2015; pp. 169-186.

2. American College of Sports Medicine. ACSM's Resource Manual for Guidelines for Exercise Testing and Prescription; Lippincott Williams \& Wilkins: Philadelphia, PA, USA, 2012.

3. Elliott, T.B.; Elliott, B.A.; Bixby, M.R. Risk factors associated with camp accidents. Wilderness Environ. Med. 2003, 14, 2-8. [CrossRef] 
4. Simpson, K.M.; Munro, B.J.; Steele, J.R. Backpack load affects lower limb muscle activity patterns of female hikers during prolonged load carriage. J. Electromyogr. Kinesiol. 2011, 21, 782-788. [CrossRef] [PubMed]

5. Silder, A.; Delp, S.L.; Besier, T. Men and women adopt similar walking mechanics and muscle activation patterns during load carriage. J. Biomech. 2013, 46, 2522-2528. [CrossRef]

6. Keren, G.; Epstein, Y.; Magazanik, A.; Sohar, E. The energy cost of walking and running with and without a backpack load. Eur. J. Appl. Physiol. Occup. Physiol. 1981, 46, 317-324. [CrossRef]

7. Browning, R.C.; Modica, J.R.; Kram, R.; Goswami, A. The effects of adding mass to the legs on the energetics and biomechanics of walking. Med. Sci. Sport Exerc. 2007, 39, 515-525. [CrossRef]

8. Huang, T.W.; Kuo, A.D. Mechanics and energetics of load carriage during human walking. J. Exp. Biol. 2014, 217, 605-613. [CrossRef]

9. Morrison, A.; Hale, J.; Brown, S. Joint range of motion entropy changes in response to load carriage in military personnel. Hum. Mov. Sci. 2019, 66, 249-257. [CrossRef]

10. Liew, B.X.W.; Morris, S.; Netto, K. The effects of load carriage on joint work at different running velocities. J. Biomech. 2016, 49, 3275-3280. [CrossRef]

11. Loverro, K.L.; Hasselquist, L.; Lewis, C.L. Females and males use different hip and knee mechanics in response to symmetric military-relevant loads. J. Biomech. 2019, 95, 109280. [CrossRef]

12. Krajewski, K.T.; Dever, D.E.; Johnson, C.C.; Rawcliffe, A.J.; Ahamed, N.U.; Flanagan, S.D.; Mi, Q.; Anderst, W.J.; Connaboy, C. Load carriage magnitude and locomotion strategy alter knee total joint moment during bipedal ambulatory tasks in recruit-aged women. J. Biomech. 2020, 105, 109772. [CrossRef]

13. Lay, A.N.; Hass, C.J.; Gregor, R.J. The effects of sloped surfaces on locomotion: A kinematic and kinetic analysis. J. Biomech. 2006, 39, 1621-1628. [CrossRef] [PubMed]

14. Holt, K.G.; Wagenaar, R.C.; LaFiandra, M.E.; Kubo, M.; Obusek, J.P. Increased musculoskeletal stiffness during load carriage at increasing walking speeds maintains constant vertical excursion of the body center of mass. J. Biomech. 2003, 36, 465-471. [CrossRef]

15. Walsh, G.S.; Low, D.C.; Arkesteijn, M. Effect of stable and unstable load carriage on walking gait variability, dynamic stability and muscle activity of older adults. J. Biomech. 2018, 73, 18-23. [CrossRef] [PubMed]

16. Huang, L.; Yang, Z.; Wang, R.; Xie, L. Physiological and biomechanical effects on the human musculoskeletal system while carrying a suspended-load backpack. J. Biomech. 2020, 108, 109894. [CrossRef]

17. Yang, L.; Zhang, J.; Xu, Y.; Chen, K.; Fu, C. Energy Performance Analysis of a Suspended Backpack with an Optimally Controlled Variable Damper for Human Load Carriage. Mech. Mach. Theory 2020, 146, 103738. [CrossRef]

18. Franz, J.R.; Kram, R. The effects of grade and speed on leg muscle activations during walking. Gait Posture 2012, 35, 143-147. [CrossRef]

19. Pickle, N.T.; Grabowski, A.M.; Auyang, A.G.; Silverman, A.K. The functional roles of muscles during sloped walking. J. Biomech. 2016, 49, 3244-3251. [CrossRef]

20. Alexander, N.; Schwameder, H. Effect of sloped walking on lower limb muscle forces. Gait Posture 2016, 47, 62-67. [CrossRef]

21. Voloshina, A.S.; Kuo, A.D.; Daley, M.A.; Ferris, D.P. Biomechanics and energetics of walking on uneven terrain. J. Exp. Biol. 2013, 216, 3963-3970. [CrossRef]

22. Haggerty, M.; Dickin, D.C.; Popp, J.; Wang, H. The influence of incline walking on joint mechanics. Gait Posture 2014, 39, 1017-1021. [CrossRef]

23. Alexander, N.; Strutzenberger, G.; Ameshofer, L.M.; Schwameder, H. Lower limb joint work and joint work contribution during downhill and uphill walking at different inclinations. J. Biomech. 2017, 61, 75-80. [CrossRef]

24. Alexander, N.; Schwameder, H. Lower limb joint forces during walking on the level and slopes at different inclinations. Gait Posture 2016, 45, 137-142. [CrossRef] [PubMed]

25. Son, H. The Effect of Backpack Load on Muscle Activities of the Trunk and Lower Extremities and Plantar Foot Pressure in Flatfoot. J. Phys. Ther. Sci. 2013, 25, 1383-1386. [CrossRef]

26. Collins, S.H.; Adamczyk, P.G.; Ferris, D.P.; Kuo, A.D. A simple method for calibrating force plates and force treadmills using an instrumented pole. Gait Posture 2009, 29, 59-64. [CrossRef] [PubMed]

27. Behnke Robert, S. Kinetic Anatomy; Human Kinetics: Champaign, IL, USA, 2006.

28. Ehlen, K.A.; Reiser, R.F.; Browning, R.C. Energetics and biomechanics of inclined treadmill walking in obese adults. Med. Sci. Sports Exerc. 2011, 43, 1251-1259. [CrossRef] [PubMed] 
29. Mills, P.M.; Barrett, R.S.; Morrison, S. Agreement between footswitch and ground reaction force techniques for identifying gait events: Inter-session repeatability and the effect of walking speed. Gait Posture 2007, 26, 1-326. [CrossRef] [PubMed]

30. Pirker, W.; Katzenschlager, R. Gait disorders in adults and the elderly. Wien. Klin. Wochenschr. 2017, 129, 81-95. [CrossRef]

31. Chen, S.-K.; Wu, M.-T.; Huang, C.-H.; Wu, J.-H.; Guo, L.-Y.; Wu, W.-L. The analysis of upper limb movement and EMG activation during the snatch under various loading conditions. J. Mech. Med. Biol. 2013, 13, 1350010. [CrossRef]

32. Liu, Y.; Hong, Y.; Ji, L. Dynamic Analysis of the Abnormal Isometric Strength Movement Pattern between Shoulder and Elbow Joint in Patients with Hemiplegia. J. Healthc. Eng. 2018, 2018. [CrossRef]

33. Konrad, P. The abc of emg. Pract. Introd. Kinesiol. Electromyogr. 2005, 1, 30-35.

34. Guan, X.; Liu, Y.; Gao, L.; Ji, L.; Wang, R.; Yang, M.; Ji, R. Trunk muscle activity patterns in a person with spinal cord injury walking with different un-powered exoskeletons: A case study. J. Rehab. Med. 2016, 48, 390-395. [CrossRef] [PubMed]

35. Guan, X.; Kuai, S.; Song, L.; Li, C.; Liu, W.; Liu, Y.; Ji, L.; Wang, R.; Zhang, Z. How Height and Weight of Patients with Spinal Cord Injury Affect the Spring Locations of Unpowered Energy-stored Exoskeleton. In Proceedings of the 41st Annual International Conference of the IEEE Engineering in Medicine and Biology Society (EMBC), Berlin, Germany, 23-27 July 2019.

36. Rupert, G., Jr. Simultaneous Statistical Inference; Springer Science \& Business Media: Berlin/Heidelberg, Germany, 2012.

37. Harman, E. The effects on gait timing, kinetics and muscle activity of various loads carried on the back. Med. Sci. Sports Exerc. 1992, 24, S129. [CrossRef]

38. Harman, E.; Hoon, K.; Frykman, P.; Pandorf, C. The Effects of Backpack Weight on the Biomechanics of Load Carriage; Army Research Institute of Environmental Medicine: Natick, MA, USA, 2000.

39. Attwells, R.L.; Birrell, S.A.; Hooper, R.H.; Mansfield, N.J. Influence of carrying heavy loads on soldiers' posture, movements and gait. Ergonomics 2006, 49, 1527-1537. [CrossRef] [PubMed]

40. McGowan, C.P.; Neptune, R.R.; Clark, D.J.; Kautz, Z.A. Modular control of human walking: Adaptations to altered mechanical demands. J. Biomech. 2010, 43, 412-419. [CrossRef]

41. Dorn, T.W.; Wang, J.M.; Hicks, J.L.; Delp, S.L. Predictive Simulation Generates Human Adaptations during Loaded and Inclined Walking. PLoS ONE 2015, 10. [CrossRef] [PubMed] 